EDITOR

Roger Jones, FRCP, FRCGP

London

DEPUTY EDITOR

Alec Logan, FRCGP

Motherwell

JOURNAL MANAGER

Catharine Hull

SENIOR ASSISTANT EDITOR

Erika Niesner

ASSISTANT EDITOR

Moira Davies-Cinar

EDITORIAL ASSISTANT

Tania Marszalek

ADVERTISING EXECUTIVE

Brenda Laurent

CLASSIFIED ADVERTISING SALES EXECUTIVE Peter Wright

EDITORIAL BOARD

Richard Baker, MD, FRCGP

Leicester

Stephen Barclay, MD, FRCGP, DRCOG

Cambridge

Chris Butler, MD, MRCGP

Cardiff

Kath Checkland, PhD, MRCGP

Manchester

Mark Gabbay, MD, FRCGP

Liverpool

Clare Gerada, MBE, FRCGP, MRCPsych London

Murray Lough, MD, FRCGP

Glasgow

David Mant, MD, FRCGP

Oxford

Tim Peters, MSc, PhD, CStat, FFPH

Bristol

Chris Salisbury, MD FRCGP

Bristol

John Sandars, MSc, MD, FRCGP, MRCP

Leeds

Mark Shapley, FRCGP, DCH, DRCOG

Newcastle-under-Lyme

Niroshan Siriwardena, MMedSci, PhD

FRCGP

Lincoln

Theo Verheij, MD, PhD, MRCGP

Utrecht, The Netherlands

Sue Wilson, BA, PhD, PGA

Birmingham

2008 impact factor: 2.278

EDITORIAL OFFICE

14 Princes Gate, London SW7 1PU

(Tel: 0207581 3232, Fax: 0207584 6716).

E-mail: journal@rcgp.org.uk

http://www.rcgp.org.uk/bjgp

PUBLISHED BY

The Royal College of General Practitioners,

14 Princes Gate, London SW7 1PU. Registered charity number 223106. The BJGP is published by the RCGP, but has complete editorial

independence. Opinions expressed in the BJGP should not be taken to represent the policy of

the RCGP unless this is specifically stated.

No endorsement of any advertisement is implied or intended by the RCGP.

PRINTED IN GREAT BRITAIN BY

HPM Limited, Prime House, Park 2000,

Heighington Lane Business Park

Newton Aycliffe, Co. Durham DL5 6AR.

Printed on $100 \%$ recycled paper

May Focus

\section{QUESTIONS FOR THE GP CURRICULUM}

The central importance of the personal primary care physician is one of the messages in Larry Green's editorial' ${ }^{1}$ on the healthcare reforms which are planned and needed in the UK and the US. Even before the financial winter, the shift of the focus of care of many patients from the secondary (hospital) sector to the primary (general practice and family medicine) sector had been recognised as holding the key to affordable and comprehensive medicine. The planned reconfigurations of hospital services and the amplification of the secondary-primary shift make it more important than ever for primary care physicians and their teams to be adequately equipped for the job. And the job is changing. Management of the major noncommunicable diseases is becoming increasingly complex and challenging, each year seems to bring a new threat from a new infectious disease and the changing demography and expectations of our patients have new implications for medical practice. Some of these challenges are well illustrated by the papers in this month's Journal.

The studies on sleep problems - insomnia and sleep apnoea ${ }^{2-4}$ - draw attention to a neglected and under-researched area of primary care practice, and remind us of the significance of sleep disturbances in patient's lives. The identification of sleep apnoea and the management of sleeplessness are not straightforward and are probably topics for which recently-trained GPs are likely to feel illequipped. Dealing with HIV-positive patients in general practice and the incorporation of an informed approach to the acquisition and interpretation of genetic information are two further topics which also highlight problems for primary care clinicians. ${ }^{5}$ None of these subjects are likely to have been routinely covered in the undergraduate curriculum and may well not have been dealt with in-depth during postgraduate training.

Just as the research required to inform effective, evidence-based primary care practice cannot simply be transferred from secondary care settings to primary care, so education for practice needs to be provided in the right context. The increasing complexities of chronic disease management require increasingly sophisticated training. The recent decision by Medical Education England not to approve an extended training programme for general practice is a considerable disappointment and seriously threatens the capabilities of the next generation of GPs to take on the new responsibilities that health service reform will undoubtedly imply. An extended, flexible curriculum, offering additional specialist internal medicine experience and more time in practice, learning to cope with 'the new primary care,' is essential if general practice is to meet the expectations that will inevitably be placed upon it. The current 3-year programme - with 2 years in hospital and one in practice - is out of step with many western European countries, looks decidedly thin compared with specialist training in other disciplines, and is an unsatisfactory platform for the career development of the next cadre of academic GPs required to lead teaching and research in the future. Extended vocational training could, for example, include Masters level study for graduates wishing to prepare for academic training fellowships and educational careers for those wishing to take their skills in clinical medicine and health services management to higher levels - the foundations for a meaningful career structure for general practice.

By the time the next issue of the BJGP is published we will know who is governing the UK. Some of the main parties' proposals for the future of the NHS appear to represent sensible ideas for progress. ${ }^{6}$ Yet some have already met with resistance from clinicians and managers who wish to cling to an unsatisfactory status quo. While reorganisation fatigue is a well accepted sideeffect of health service reform, it now seems impossible for us to stand still and survive. Many of the longstanding pathologies of our system, perhaps most damagingly, the deep divide between primary and secondary care, and the failure to work creatively and efficiently together, require urgent attention. Leadership, goodwill, and flexibility are required of us all.

\section{Roger Jones}

Editor

\section{REFERENCES}

1. Green L. Healthcare reform in the UK and the US: what lies beneath? Br J Gen Pract 2010; 60(574): 315-316.

2. Di Guardo A, Profeta G, Crisafulli C, et al. Obstructive sleep apnoea in patients with obesity and hypertension. $\mathrm{Br} \mathrm{J} \mathrm{Gen}$ Pract 2010; 60(574): 325-328.

3. Dyas JV, Apekey TA, Tilling M, et al. Patients' and clinicians experiences of consultations in primary care for sleep problems and insomnia: a focus group study. Br J Gen Pract 2010; DOI: 10.3399/bjgp10X484183.

4. Hayward R, Jordan K, Croft P. Healthcare use in adults with insomnia: a longitudinal study. Br J Gen Pract 2010; 60(574): 334-340.

5. Defty $\mathrm{H}$, Smith $\mathrm{H}$, Kennedy M, et al. GPs' perceived barriers to their involvement in caring for patients with HIV: a questionnaire-based study. Br I Gen Pract 2010; 60(574): 348-351.

6. Jones R. Keeping the NHS on course: politicans' proposals for the next 4 years. Br J Gen Pract 2010; 60(574): 378-380.

DOI: 10.3399/bjgp10X484110

(c) British Journal of General Practice 2010; 60: 313-392. 